\title{
ОСОБЕННОСТИ ПРАВОВОГО ПОЛОЖЕНИЯ ЛАБОРАТОРНЫХ ЖИВОТНЫХ: ПОСТАНОВКА ПРОБЛЕМЫ
}

\begin{abstract}
Аннотация: В статье обсуждается проблематика правового положения лабораторных животных, как особой категории объектов права. Предметом данного исследования выступает российское законодательство в сфере регулирования, используемых в опытах, лабораторных животных. Несмотря на распространение гуманистических принципов и идеологии бережного отношения к природе, проработка проблемы этой категории животных на данный момент недостаточно. В данной исследовательской работе обсуждаются те основания, которые обуславливают специифику и значимость данного направления в системе современного права. В качестве методов данного исследования выступили теоретический анализ российской и зарубежной научной литературы, а также сравнительный анализ базовых аспектов прав животных в России и за рубежом. Данная работа представила все основные положения правового регулирования использования в научных экспериментах лабораторных животных, что до сих пор было лишь отрывочно описано в работах современных исследователей. Данная категория животных не попадает под действие фаунистического законодательства, но особый порядок их использования не регламентируется и нормами гражданского права. В данном случае действует специальное законодательство, которое до сих пор находящееся в России на стадии своего формирования.

Abstract: This article discusses the problematics of the legal status of laboratory animals as a separate category of legal objects. The subject of this research is the Russian legislation in the field of regulation on the laboratory animals used in experiments. Despite the propagation of the humanistic principles and ideology of gentle attitude towards nature, there is still insufficient progress made in resolving this problem. This research discusses the bases that substantiate the specific nature and significance of this issue within the modern legal system. This work presents all the main positions of legal regulation on the use of animals in scientific experiments, which until now was only partially described in the works of modern researches. This category of animals does not fall under the faunistic legislation, but the specific manner in which they are used is not subject to the norms of the civil law. The special legislation that applies in this case is still at a stage of development within the Russian Federation.
\end{abstract}

Ключевые слова: Права животных, лабораторные животные, защитаживотных, экспериментальная деятельность, опыты на животных, правовое государство, животный мир, 3R, правоотношения, вивисекция.

Keywords: Animal rights, laboratory animals, animal protection, experimental work, experiments on animals, wildlife, $3 R$, vivisection.

огласно исследованию «Британского союза за отмену вивисекции» (British Union for the Abolition of Vivisection - BUAV) $)^{1}$ и «Наффилдского совета по биоэтике» (Nuffied Council on Bioethics) ${ }^{2}$ во всем мире ежегодно используется до 100 млн лабораторных животных, около 12 млн из которых в странах Европейского Союза. При этом полученные в ходе исследования данные не включают в это число беспозвоночных (например, drosophila melanogaster), новорожденных (большинство лабораторий не ведёт подсчёт их количества) и помеченных, как «избыточные», животных.

Не смотря на повсеместность использования в биологических и медицинских экспериментах лабораторных животных, не редки случаи, когда опыты на животных приводили к

\footnotetext{
${ }^{1}$ British Union for the Abolition of Vivisection - британская организация выступающая за отмену любых опытов на животных.

${ }^{2}$ Nuffield Council on Bioethics - британская независимая благотворительная организация, работа которой сосредосточена на рассмотрении этических вопросов, взникающих в свете новых достижений в области биологических и медицинских исследований.
}

неправильным выводам, например о пользе и безопасности изучаемого препарата. Причина неправильных результатов кроется в физиологических различиях между экспериментальными животными и человеком. Один и тот же исследуемый лекарственный препарат может привести к различным реакциям у разных животных и человека, например, морфий оказывает седативный эффект на организмы человека, крыс и собак, но при этом сменяет эффект на противоположный у кошек, коз и лошадей; другой пример - аспирин, который не смотря на положительные свойства для человека, ядовит для кошек; а пенициллин для морских свинок.

Разница в реакциях на различные токсичные вещества у животных и человека может быть следствием существенных различий в абсорбции, особенностях кишечной флоры, в распределении в тканях, в обмене веществ, включая биоинтоксикацию и детоксикацию, в скорости и механизмах восстановления и выделения. Ярко выраженные различия обменных процессов и механизмов интоксикации отражаются в исследованиях на уровне клеточного метаболизма. Это заметно усложняет использование данных, полученных в экспериментах с животными при работе с человеческим ор- 
DOI: $10.7256 / 1811-9018.2014 .12 .13346$

При цитировании этой статьи сноска на doi обязательна

\section{Право и политика $12(180) \cdot 2014$}

ганизмом. Тем не менее многие современные биологические, медицинские, фармацевтические и другие научные открытия осуществляются с использованием экспериментальных животных, которые используются в качестве тест-объектов, так как альтернативные модели экспериментов, т.е. без использования животных, до сих пор не могут полностью имитировать сложный организм человека и происходящие в нем процессы.

Великобритания стала первой страной в мире, в которой был принят закон о защите экспериментальных животных, произошло это в 1876 г. Первые же законодательные акты, вставшие на защиту животных, появились в Европе еще в начале XIX века. Сначала закон был принят в Великобритании в 1822 г., затем во Франции (1850 г.) и в Германии (1871 г.).

Германия пошла дальше других и стала первой в мире страной, где в мае 2002 г. защита прав животных была внесена в главный документ страны - Конституцию ФРГ, данные поправки были внесены в статье 20а. Во многом это была заслуга общественных организаций (Tierschutzverein) - обществ защиты животных, которые распространены и ведут активную деятельность в каждой из земель Германии. Кроме того на территории ФРГ действует специальный «Закон о Защите животных» (Tierschutzgesetz) ${ }^{3}$, а также «Распоряжение по содержанию собак» (Hundeverordnung) ${ }^{4}$, так же на законодательном уровне утверждена система приютов для животных.

Немецкий “Закон о Защите животных” состоит из 20 параграфов, 7-9 параграфы данного закона регулируют эксперименты на животных. Положения параграфов о правовом регулировании опытов с лабораторными животными большей своей частью совпадающие с "Хельсинкской декларацией" принятой Всемирной медицинской ассоциацией в 2000 г.

“Закон о защите животных” (ФРГ) и "Хельсинская декларация" в своих основных положениях содержат требования об условиях использования лабораторных животных в качестве тест-моделей при проведении научных экспериментов:

1. Испытания на животных должны быть спланированы и осуществляться только лицами, которые имеют необходимые для этого знания и навыки.

2. Условия содержания животных в виварии (клинике) должны обеспечивать для них нормальный биологический фон и полностью соответствовать требованиям СНИП.

3. Все процедуры на экспериментальном животном, которые могут стать причиной боли или иного рода мучительного состояния, должны производиться с использованием обезболивающих препаратов.

4. В послеоперационный период экспериментальное животное должно получать квалифицированный уход специалиста и адекватное обезболивание.

5. Запрещается использование животного для болезненных процедур более чем один раз, кроме тех животных, которые используются для контрольных экспериментов в хронической серии.

6. По завершении учебных или научных манипуляций на животном, приводящих к нарушению его физиологиче-

${ }^{3}$ Tierschutzgesetz. URL: http://www.gesetze-im-internet.de/tierschg/ index.html

${ }^{4}$ Tierschutz-Hundeverordnung. URL: https://www.juris.de/purl/gesetze/_ges/TierSchHuV

${ }^{5}$ Хельсинкская декларация Всемирной медицинской ассоциации от 2000 г. URL: http://acto-russia.org/files/WMA_Helsinki.doc ских функций и жизнеспособности, животное должно быть своевременно умерщвлено с соблюдением всех требований гуманности.

Следует также добавить, что исследования не могут проводиться с использованием лабораторных животных, если существуют другие замещающие способы получения соответствующих научных результатов, в тех же случаях, когда проведение опыта невозможно без использования животных, в экспериментах следует полагаться на принципы, сформулированные Расселом и Берчем (Russel \& Burch) ${ }^{6}$ - принцип 3R:

a) reduction - максимально возможное снижние числа экспериментальных животных, используемых для осуществления необходимых учебных или научных целей;

б) refinement - улучшение, совершенствование экспериментальных методик для снижения (исключения) отрицательных (болевых, стрессирующих и др.) влияний на лабораторное животное;

в) replacement - устранение лабораторных животных из экспериментальной или учебной работы, если есть возможность получить аналогичные результаты альтернативными научными методами.

Не смотря на устойчивую тенденцию к снижению числа экспериментов с использованием животных во всех развитых странах, но это ситуация не везде одинакова.

В России законодательное регулирование проведения опытов на экспериментальных животных в настоящее время не достаточно развито.

Установлено, что жестокое обращение в отношении лабораторных животных - это, в частности, использование животных для ненаучных исследований, причинение им в ходе экспериментов неоправданных страданий, использование мучительного способа умерщвления, содержание лабораторных животных, в условиях которые не соответствуют биологическим потребностям данного вида, проведение на животном жестокого эксперимента без анестезии или жестокое выведение животного из эксперимента.

Отношения в области охраны и использования объектов животного мира в России, содержащихся в научных целях в искусственной среде обитания, включены в сферу действия Федерального закона №52-Ф3 от 24 апреля 1995 г. «О животном мире» $7^{7}$ - статья 3, абзац 2.

В Уголовном кодексе РФ (УК РФ) предусмотрена ответственность за жестокое обращение с животными, влекущее к их гибели или увечью, в случае если это деяние совершено из хулиганских или корыстных побуждений, или в тех случаях, когда применяются садистские методы, или в присутствии малолетних. В подобных случаях, в соответствии со статьёй 245 УК РФ предусматривается наказание в виде лишения свободы до двух лет. Однако на практике наказание в соответствии с данной статьёй наступает чрезвычайно редко.

Согласно статье 137 Гражданского кодекса РФ (ГК РФ), к животным применяются общие правила об имуществе, поскольку законом или иными правовыми актами не установлено иное. Но стоит отметить, что при осуществлении прав не допускается жестокое обращение с животными, противоречащее

\footnotetext{
${ }^{6}$ Russell W.M.S. and Burch R.L. The Principles of Humane Experimental Technique. London: Methuen. 1959. 238 pp.

7 Федеральный закон от 24.04.1995 N 52-Ф3 (ред. от 07.05.2013) «О животном мире» (24 апреля 1995 г.)
} 
DOI: $10.7256 / 1811-9018.2014 .12 .13346$

При цитировании этой статьи сноска на доі обязательна

Человек и окружающая среда

принципам гуманности. В соответствии с частью 2 статьи 231 ГК РФ возврат найденного безнадзорного животного прежнему хозяину, должен осуществляться с непременным учётом привязанности самого найденного животного, что уже по своей сути исключает определение животного как вещи.

Подобная двойственность в определении приводит к целому ряду коллизий в правовом регулировании отношений по использованию и охране объектов животного мира. Действующее российское законодательство не содержит нормы-дефиниции, распространяющейся на всех животных и содержащей четкие указания на квалификационные признаки, позволяющие отнести те или иные живые организмы к какой-либо категории животных как объектов правоотношений. При этом особый правовой режим предусмотрен для лабораторных животных, которые не могут быть непосредственно отнесены ни к диким, ни к домашним животным. Дело в том, что из-за отсутствия чётких признаков среди лабораторных животных могут оказаться как животные, традиционно относящиеся к диким (например, мышь, волк или зяблик), так и обычно относящиеся к домашним (домашняя собака или кошка) ${ }^{8}$. По причине вышеуказанного признака “состояния естественной свободы" данные животные не попадают под действие особого фаунистического законодательства, но особый порядок их использования не регламентируется и с помощью норм гражданского права. В данном случае подобные животные должны подпадать под действие специального законодательства, которое в России до сих пор находящееся в стадии своего формирования.

В качестве российского аналога европейскому закону о защите животных был предложен проект закона «О защите животных от жестокого обращения».

В данном проекте впервые была предложена подробная классификация животных, которая, кроме всего прочего, включала экспериментальных животных как отдельную категорию. В статье 10 данного проекта закона «О защите животных от жестокого обращения» было предусмотрено, что животное может быть использовано в эксперименте только при отсутствии других альтернативных тест-моделей и мето- дов. В случае использования экспериментальных животных организация должна иметь обязательное лицензирование исследовательских работ; использовать обязательное обезболивание лабораторных животных при всех болезненных процедурах; запрещение использования хирургической девокализации животных, травмирующих методов изъятия животных из клеток, а также применение экспериментов с повреждающим воздействием в образовательном процессе лиц дошкольного возраста9.

Однако 3 января 2000 г. было наложено вето на данный законопроект, и вот уже 14 лет российские защитники животных не могут добиться принятия этого, одного из самых необходимых и значимых для современной России закона.

В 2011 году по инициативе премьер-министра Российской Федерации Д.А. Медведева в российском парламенте был подготовлен к рассмотрению проект Федерального Закона «Об ответственном отношении к животным», который был принят в первом чтении 24 марта 2011 г., после чего был отправлен на доработку, которая ведется уже несколько лет и сроки окончания которой до сих пор не установлены.

Таким образом можно сделать вывод, что российское законодательство требует существенного развития в области регулирования прав животных, более того, в отличие от зарубежного законодательства, в нём не выделена довольно большая по количеству категория - лабораторные животные. Выделение данной категории необходимо в связи с бурным развитием медицинских, биологических и других опытов, осуществляемых на животных, возможно в будущем будет создан полный аналог животной модели техническими средствами, но до тех пока это не так, лабораторные животные должны быть выделены в отдельную правовую категорию.

Совершенствование данного законодательства крайне необходимо и в плане защиты самих животных, и в плане морально-нравственного воспитания молодежи и развития духовности, нравственности, бережного отношения к окружающему миру, ответственности и психического здоровья всего населения страны.

\section{Библиография:}

1. Анисимов А.П., Копылов Д.Э., Мохов А.А. Правовой режим животных как объекта гражданских и иных правоотношений // Современное право. - 2007.-№ 4. - С. 93-98.

2. Гражданский кодекс РФ от 30.11.1994 N 51-Ф3 (ред. от 05.05.2014)

3. Уголовный кодекс РФ от 13.06.1996 N 63-ФЗ (ред. от 21.07.2014)

4. Федеральный закон от 24.04.1995 N 52-Ф3 (ред. от 07.05.2013) «О животном мире» (24 апреля 1995 г.)

5. Хельсинкская декларация Всемирной медицинской ассоциации (2000г.) URL: http://acto-russia.org/files/WMA_Helsinki.doc

6. Х Хромова Ю.Р. экспериментальное животное: основы правового регулирования // Медицинское право. 2004. №22. С. $20-24$.

7. Russell W.M.S. and Burch R.L. The Principles of Humane Experimental Technique. London: Methuen. 1959. 238 pp.

8. Tierschutzgesetz. URL: http://www.gesetze-im-internet.de/tierschg/index.html

9. Tierschutz-Hundeverordnung. URL: https://www.juris.de/purl/gesetze/_ges/TierSchHu

10. Кухарук В.В. Опасные воздействия на психические функции человека и проблемы их уголовно-правового регулирования // NB: Вопросы права и политики. - 2013. - 5. - C. 64 - 82. DOI: 10.7256/2305-9699.2013.5.783. URL: http://www.e-notabene.ru/lr/article_783.html

\section{References (transliterated):}

1. Anisimov A.P., Kopylov D.E., Mokhov A.A. Pravovoi rezhim zhivotnykh kak ob"ekta grazhdanskikh i inykh pravootnoshenii // Sovremennoe pravo. - 2007.-№ 4. - S. 93-98.

${ }^{8}$ Анисимов А.П., Копылов Д.Э., Мохов А.А. Правовой режим животных как объекта гражданских и иных правоотношений // Современное право. - 2007. - № 4. - С. 93-98.

${ }^{9}$ Проект Федерального Закона «О защите животных от жестокого об-
pащения». URL: http://www.vita.org.ru/law/Zakonu/stop-cruelty.htm\#2 
DOI: $10.7256 / 1811-9018.2014 .12 .13346$

При цитировании этой статьи сноска на dоі обязательна

\section{Право и политика $12(180) \cdot 2014$}

2. Khromova Yu.R. eksperimental’noe zhivotnoe: osnovy pravovogo regulirovaniya // Meditsinskoe pravo. 2004. №2. S. 20-24.

3. Russell W.M.S. and Burch R.L. The Principles of Humane Experimental Technique. London: Methuen. 1959. 238 pp.

4. Tierschutzgesetz. URL: http://www.gesetze-im-internet.de/tierschg/index.html

5. Tierschutz-Hundeverordnung. URL: https://www.juris.de/purl/gesetze/_ges/TierSchHu

6. Kukharuk V.V. Opasnye vozdeistviya na psikhicheskie funktsii cheloveka i problemy ikh ugolovno-pravovogo regulirovaniya // NB: Voprosy prava i politiki. - 2013. - 5. - C. 64 - 82. DOI: 10.7256/2305-9699.2013.5.783. URL: http://www.e-notabene.ru/lr/article_783.html 